Article

\title{
Contamination of Animal Feed with Undeclared Tetracyclines-Confirmatory Analysis by Liquid Chromatography-Mass Spectrometry after Microbiological Plate Test
}

\author{
Monika Przeniosło-Siwczyńska *, Ewelina Patyra ${ }^{D}$, Aleksandra Grelik, Maja Chyłek-Purchała, \\ Beata Kozak and Krzysztof Kwiatek \\ Department of Hygiene of Animal Feedingstuffs, National Veterinary Research Institute, \\ Partyzantow 57 Avenue, 24-100 Pulawy, Poland; ewelina.patyra@piwet.pulawy.pl (E.P.); \\ aleksandra.grelik@piwet.pulawy.pl (A.G.); maja.purchala@piwet.pulawy.pl (M.C.-P.); \\ beata.kozak@piwet.pulawy.pl (B.K.); kwiatekk@piwet.pulawy.pl (K.K.) \\ * Correspondence: monika.przenioslo@piwet.pulawy.pl
}

Received: 8 April 2020; Accepted: 29 April 2020; Published: 5 May 2020

check for updates

\begin{abstract}
The presence of tetracycline (TC) antibiotics was determined in animal feed that had been previously screened with a microbiological plate test. Feed samples were screened by a microbiological plate test on a pH 6.0 culture medium seeded with Bacillus cereus ATCC 11778 able to pre-reveal the presence of tetracyclines. Subsequently, confirmation and quantification were performed using a validated HPLC method with mass spectrometric detection. In 2013-2018, 353 feed samples were analysed to detect antibacterial substances, of which $186(52.7 \%)$ were suspected to contain tetracyclines. Forty-two out of $186(22.6 \%)$ samples analysed by the chromatographic method contained undeclared tetracyclines, which were determined at concentrations from 0.3 to $49 \mathrm{mg} \mathrm{kg}^{-1}$. The most frequently identified contaminating tetracyclines were doxycycline and chlortetracycline.
\end{abstract}

Keywords: antibiotics; tetracyclines; feed analysis; microbial screening assay; LC-MS

\section{Introduction}

Tetracyclines (TCs) are antibiotics that exhibit activity against infections caused by both Gram-positive and Gram-negative bacteria as well as chlamydia, mycoplasmas, protozoan parasites and rickettsiae [1-3]. They are widely administered to intensive farming animals because of their broad spectrum of activity and cost-effectiveness [1,4]. Since their discovery in the late 1940s, TCs have been used widely for the treatment and prophylaxis of bacterial diseases and as feed additives to promote growth in farm animals [5-7]. The emergence of bacterial resistance against tetracyclines, and the emergence of bacterial resistance against antibacterial agents in general, has caused severe drawbacks in their use. Concerns were raised on the potential problems due to the use of human antibiotics for growth promotion in animal husbandry and the transference of resistance to humans [8-10]. The discussion concluded in 1974 with the elimination of TCs as feed additives along with other antibiotics used in humans [11].

Several properties make tetracyclines the most commonly used of all antibiotics: they are active against most common pathogens, show good oral absorption, exhibit low toxicity and cause only few allergic reactions, and they are relatively inexpensive [12]. This has led to an intensive use of TCs for the treatment and prophylactic control of bacterial infections not only in humans, but also in animals. Of the eight forms of commercially available tetracyclines, four are frequently used in animal husbandry: chlortetracycline (CTC), doxycycline (DC), oxytetracycline (OTC) and tetracycline (TC). According to 
data described by Grave et al. [13] on the consumption of veterinary antimicrobial agents intended for food-producing animals, in all European countries tetracyclines, penicillins and sulfonamides accounted for more than half (range 53-88\%) of the total amount of antimicrobial agents sold by country, expressed as mg/PCU. This trend continues and, according to the ESVAC report [14] in 2017, the highest sales concerned tetracyclines, followed by penicillins and sulfonamides, accounting for $30.5 \%, 26.9 \%$ and $9.8 \%$, respectively of the total sales of veterinary antimicrobial agents.

The usage of antimicrobials in farm animals is strictly regulated in the European Union (EU) to protect consumers, as the excessive and inappropriate use of antibiotics can lead to the emergence of bacteria resistant to antibiotics or the presence of antibacterial residues on food products of animal origin [15-17]. In the EU, antibacterial substances permitted as feed additives to help fatten livestock were prohibited for non-medicinal purposes in 2006. The control and analysis of antibacterial substances in feed for farm animals has become an important issue, as only authorized feeds can be medicated under specific conditions, as stated in Regulation (EU) 2019/4 [18]. The antibacterial substances, in addition to medicated feeds, can enter feed via different paths, for instance due to unintentional cross-contamination in the feed mills or by unauthorized use for prophylaxis or to fraudulently promote growth [19]. Cross-contamination between medicated and nonmedicated feed can occur with any type of drug added to the feed, particularly when the cleaning process between batches is inefficient [20]. The fact that antibiotics could be present as contaminants in feed without farmers' knowledge implies that a withdrawal period will not be considered and, in addition to the development of antibiotic-resistant bacteria, antibiotic residues could remain in animal products (e.g., meat, eggs, milk) [21].

The effective and efficient control of the possible illegal use of undeclared antibiotics requires the availability of multi-screening and confirmation methods which can be implemented in an overall control strategy [22-24]. For the rapid detection of antibiotics in feed or food, microbiological assays are routinely used because they are easy to perform and inexpensive. However, the main disadvantage of these tests is their lack of specificity; that is, they often detect growth inhibition of a sensitive test strain, whether a substance with antimicrobial activity is present or not. The technique of choice for the confirmatory analysis of antimicrobial agents in feed is liquid chromatography coupled with mass spectrometry (MS). However, the analysis of animal feed has proved to be quite a challenge because of the high complexity and the variability of the matrix composition $[25,26]$.

This study presents an antibiotics detection system based on a microbiological screening followed by a confirmation and quantification step consisting of a suitable chemical technique, such as HPLC with MS detection. This paper focuses on the analysis of the group of antibiotics approved by the EU for therapeutic use in pigs, poultry, cattle and sheep. The tetracyclines may be added to animal feed for treating the animals as a medicated feed. However, production practices in feed mills have been identified as the main source of feed contamination [27].

Because the use of antibiotics in feeds has been prohibited in the EU for non-medicinal purposes, monitoring for undeclared or illegal use of these substances is conducted within national programmes of feed control. This paper reports the investigation on the occurrence of tetracyclines in feed used in farm animals.

\section{Results}

Out of 353 feed samples, 186 were suspected for the presence of tetracyclines, because of the presence of an inhibition zone on the B. cereus ATCC 11778 plate. The LC-MS method was adopted for the confirmatory analysis of 186 feed samples found positive by the microbial assay. After LC-MS analysis, the presence of TCs was confirmed in 42 (22.6\%) out of 186 suspect samples. Overall, the percentage of positive samples for TCs among all the analysed samples was $11.9 \%$. The results are presented in Table 1. 
Table 1. The number of samples contaminated with tetracyclines (TCs).

\begin{tabular}{cccc}
\hline Type of Sample & $\begin{array}{c}\text { Number of } \\
\text { Analysed Samples }\end{array}$ & $\begin{array}{c}\text { Number of Samples } \\
\text { Suspected of TCs }\end{array}$ & $\begin{array}{c}\text { Number of Samples } \\
\text { with TCs Confirmed }\end{array}$ \\
\hline Cattle feed & 52 & 9 & 1 \\
Pig feed & 138 & 69 & 38 \\
Poultry feed & 114 & 79 & 0 \\
Concentrates/premixes & 21 & 19 & 0 \\
Feed Materials & 28 & 10 & 3 \\
\hline Total & 353 & $186(52.7 \%)$ & $42(11.9 \%)$ \\
\hline
\end{tabular}

The most frequently identified antibiotic was doxycycline, followed by chlortetracycline (Figure 1). Doxycycline was found in 20 samples, and chlortetracycline in 11 samples. Moreover, oxytetracycline was detected in 9 samples. Furthermore, in 2 samples the presence of doxycycline in addition to tylosin was revealed.

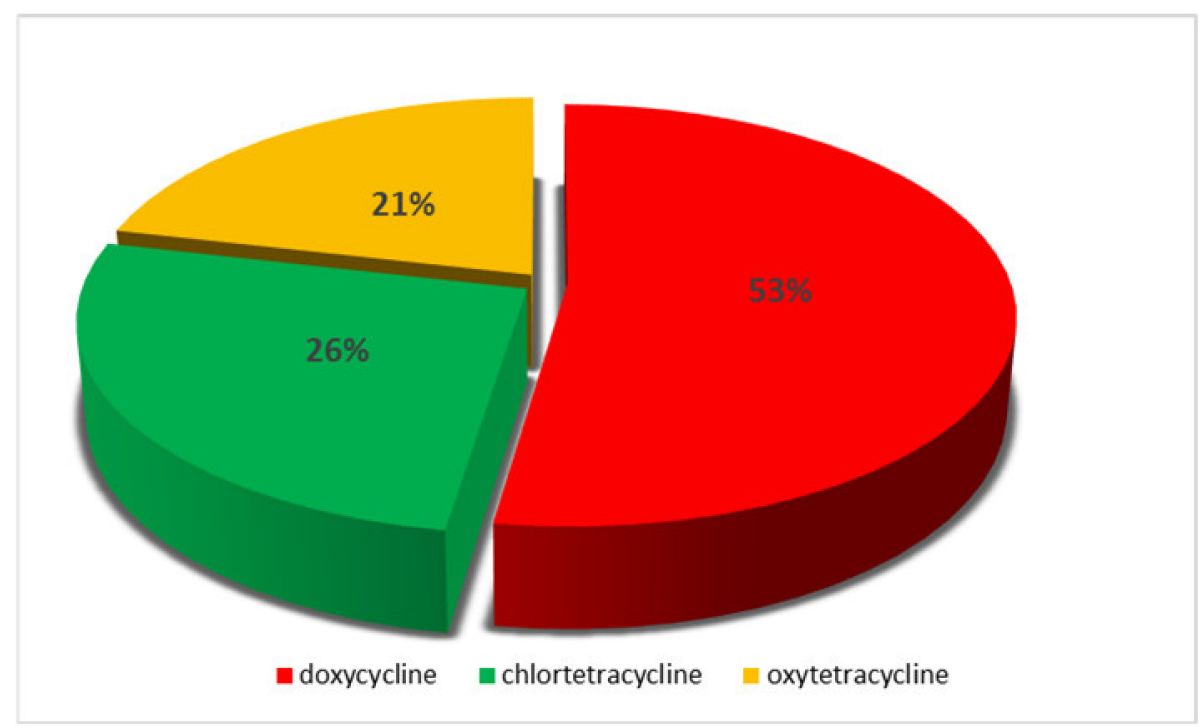

Figure 1. Percentage share of TCs revealed in the tested feed samples.

The compounds were found at concentrations from 0.3 to $49 \mathrm{mg} \mathrm{kg}^{-1}$. The results of the analytical determinations are presented in Table 2.

Table 2. The analytes and their concentrations detected in samples with an indication of the type of feed.

\begin{tabular}{cccc}
\hline Sample No. & Type of Feed & Analyte & Concentration $\mathbf{( m g ~ k g} \mathbf{~} \mathbf{)})$ \\
\hline 1 & Cattle feed & CTC & 0.3 \\
2 & Porker feed & CTC & 0.35 \\
3 & Sow feed & DC & 0.36 \\
4 & Porker feed & CTC & 0.85 \\
5 & Piglet feed & DC & 4.1 \\
6 & Pig feed & DC & 1.4 \\
7 & Porker feed & DC & 1.4 \\
8 & Sow feed & DC & 5.0 \\
9 & Pig feed & OTC & 4.7 \\
10 & Pig feed & OTC & $>5.0(49) *$ \\
11 & Pig feed & OTC & 1.8 \\
12 & Pig feed & DC & 4.6 \\
\hline
\end{tabular}


Table 2. Cont.

\begin{tabular}{|c|c|c|c|}
\hline Sample No. & Type of Feed & Analyte & Concentration $\left(\mathrm{mg} \mathrm{kg}^{-1}\right)$ \\
\hline 13 & Pig feed & OTC & $>5.0(8.1)$ \\
\hline 14 & Pig feed & OTC & 0.9 \\
\hline 15 & Sow feed & DC & 1.2 \\
\hline 16 & Porker feed & DC & $<0.3$ \\
\hline 17 & Porker feed & DC & $<0.3$ \\
\hline 18 & Porker feed & OTC & 2.3 \\
\hline 19 & Porker feed & $\mathrm{DC}$ & 0.9 \\
\hline 20 & Pig feed & DC & 4 \\
\hline 21 & Pig feed & СТC & 1.2 \\
\hline 22 & Pig feed & СТС & 1.1 \\
\hline 23 & Pig feed & CTC & $<0.3$ \\
\hline 24 & Pig feed & СТС & 2.6 \\
\hline 25 & Pig feed & СТC & $<0.3$ \\
\hline 26 & Pig feed & СТC & 2.7 \\
\hline 27 & Pig feed & СТС & 2.6 \\
\hline 28 & Porker feed & OTC & 2.8 \\
\hline 29 & Piglet feed & $\mathrm{DC}$ & 0.57 \\
\hline 30 & Piglet feed & DC & 1.5 \\
\hline 31 & Pig feed & DC & 0.47 \\
\hline 32 & Sow feed & OTC & $>5.0(5.5)$ \\
\hline 33 & Pig feed & $\mathrm{DC}$ & 0.57 \\
\hline 34 & Porker feed & СТС & 0.33 \\
\hline 35 & Piglet feed & $\mathrm{DC}$ & 0.6 \\
\hline 36 & Porker feed & DC & 2.4 \\
\hline 37 & Pig feed & OTC & $>5.0(5.7)$ \\
\hline 38 & Porker feed & DC (+tylosin) & $>5.0(7.9)(+10.9)$ \\
\hline 39 & Piglet feed & DC (+tylosin) & $3.7(+0.4)$ \\
\hline 40 & Feed material & DC & 0.6 \\
\hline 41 & Feed material & DC & 0.5 \\
\hline 42 & Feed material & DC & 0.6 \\
\hline
\end{tabular}

* The determined concentration was above the working range of the method. Approximate content is indicated in the brackets (calculated by means of a calibration curve). CTC: chlortetracycline; DC: doxycycline; OTC: oxytetracycline.

Representative chromatograms of blank feed sample, fortified feed sample and real feed samples with chlortetracycline and doxycycline, analysed by the described method, are shown in Figures 2-5.

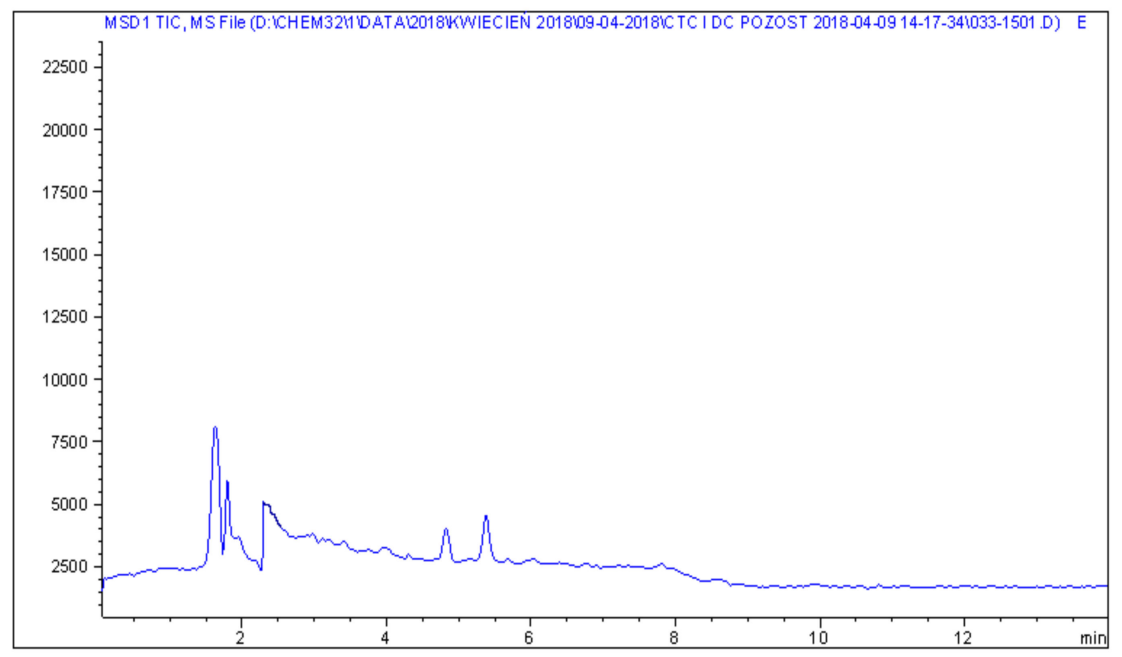

Figure 2. LC-MS chromatogram of a blank feed sample. 


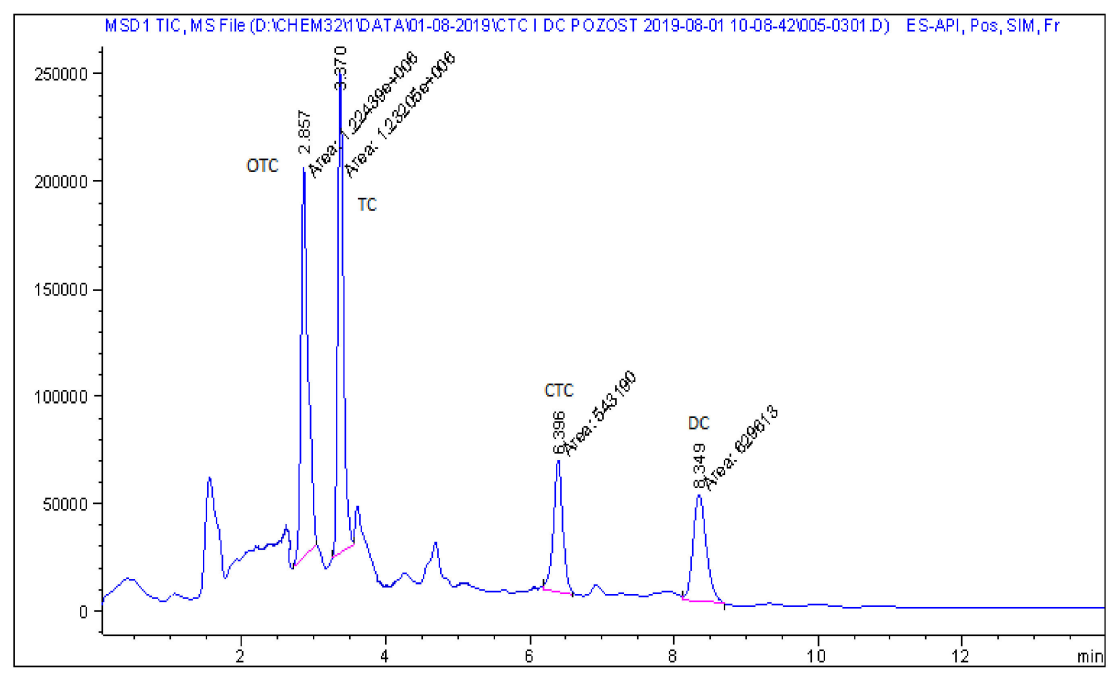

Figure 3. LC-MS chromatogram of a feed sample spiked with four tetracyclines at a concentration of $0.3 \mathrm{mg} \mathrm{kg}^{-1}$.

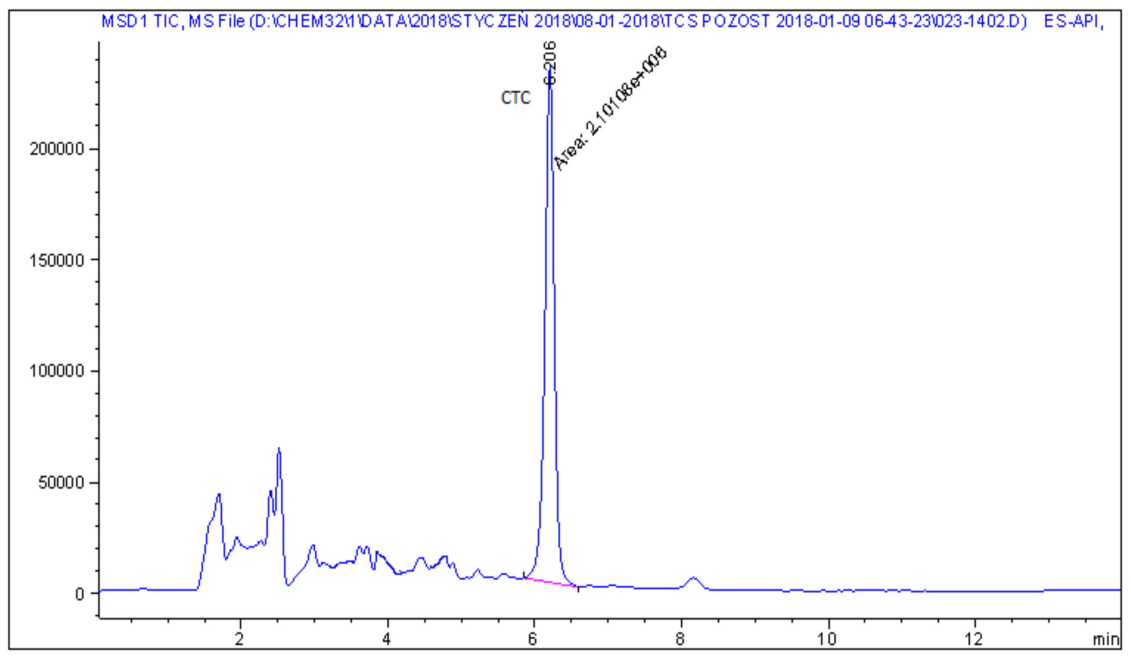

Figure 4. LC-MS chromatogram of real non-medicated feed sample with chlortetracycline at a concentration of $2.6 \mathrm{mg} \mathrm{kg}^{-1}$.

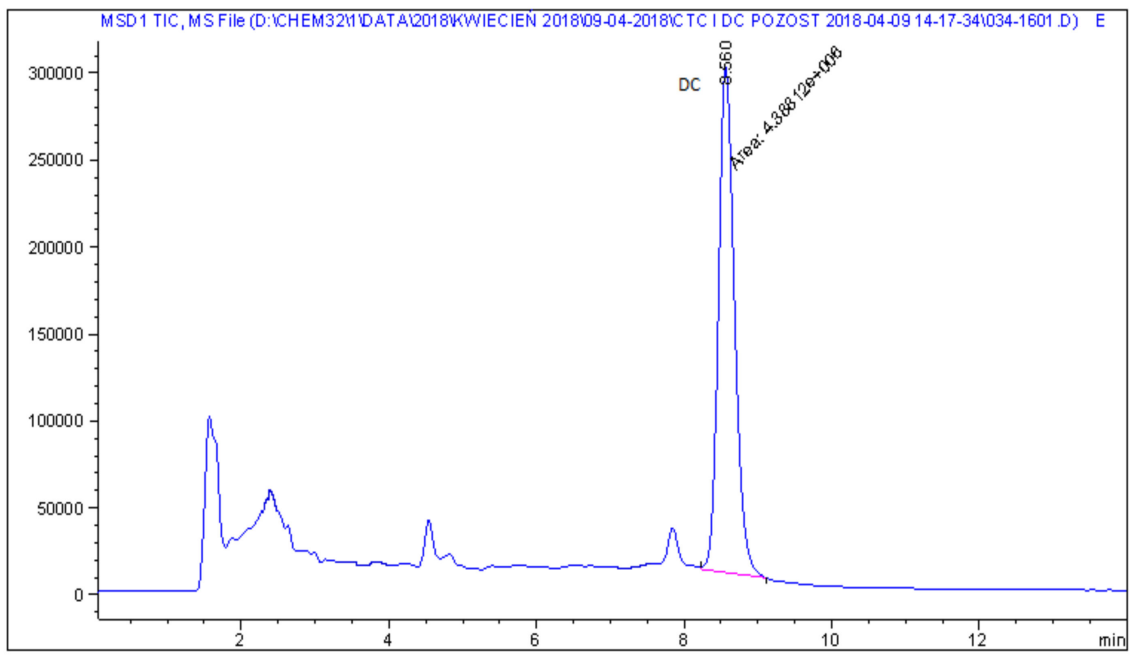

Figure 5. LC-MS chromatogram of real non-medicated feed sample with doxycycline at a concentration of $1.5 \mathrm{mg} \mathrm{kg}^{-1}$. 


\section{Discussion}

Animal feeding has become an important economic activity and has a clear impact on food safety. Animal feeds, which are the main input into livestock production, not only require adequate quality from a nutritional point of view, but must also comply with legal limits regarding contaminants and be free from the unauthorized or unintentional presence of veterinary drugs. For this reason, the analysis and control of antibacterial agents in animal feed is a very important issue. Screening tests are often used to detect the presence of antimicrobials used in farm animals. The application of microbial assays for the screening of antibacterial substances in food or feed has been widely reported in the literature [15,22-24,28-30]. Microbiological assays are screening methods that are among the most commonly used techniques for the detection of the majority of antibiotic classes, especially if a large number of samples are to be analysed. On the other hand, screening methods can have acceptable false-positive result rates. Having false-positive results is tolerable for a screening test that must be very sensitive, but not very selective. Hence, due to the risk of false-positive samples, results from microbiological assays require confirmation.

The eight-plate screening assay adopted in this study is based on the combination of $\mathrm{pH}$ conditions to favour or inhibit the antibiotic activity. Moreover, it is based on the sensitivity or resistance of the test microorganisms to various antibiotics. The combination of these factors enables a rough identification of antibiotics or antibiotic groups. In our method, eight plates used for a presumptive identification of six antibacterial families, including tetracyclines, proved to be a useful tool for the screening procedure. When all the plates are used, the pattern of inhibition can reduce unnecessary confirmatory analyses by indicating the antibacterial group most likely to be present. One of the eight plates is designed for the detection of tetracyclines owing to its low $\mathrm{pH}$ and a sensitive bacterial strain. Originally, the tetracycline family was the only one detected on the plate inoculated with B. cereus ATCC 11778.

To confirm the results obtained with the microbiological assay and to supply quantitative data, an HPLC analysis with mass-spectrometric detection was performed on the suspected and positive samples. Confirmation with HPLC or a similar technique is always necessary to identify and quantify analytes after a screening test. Due to the risk of false-positive samples, results from microbiological assays require confirmation by a confirmatory method, allowing for the selective, sensitive and accurate detection and quantification of antibiotics for effective surveillance.

Animal feed is a very complex matrix. Different animal species require different nutritive doses to get an equilibrated diet and be able to develop their specific productive functions. Poultry feeds in particular are characterized by a complex composition. In poultry, mainly commercial feeds are used; this lies in contrast to pigs, which are fed mostly production feeds. In general, feed composition may include, for example, amino acids, minerals, vitamins and salts, but also additives like organic acids, herbal mixtures or coccidiostats, or any other non-specific antibacterial substances (inhibitors) which induce matrix interference that may cause false-positive results in microbial assays. The lack of confirmed samples among poultry feeds as well as in concentrates/premixes shows that the presence of these interfering components can influence the occurrence of false-positive results. Nevertheless, microbiological methods play a crucial role in the effective official feed control and analyses.

The results showed that tetracycline antibiotics were identified in $42(11.9 \%)$ of the analysed samples. Doxycycline and chlortetracycline were found in a total of 31 (73.8\%) samples. The levels of antibiotics ranged from 0.3 to $5 \mathrm{mg} \mathrm{kg}^{-1}$. Low levels of contamination suggest cross-contamination during manufacturing in the feed mill or on the farm, although in Canada pigs can receive feed supplemented with subtherapeutic doses of chlortetracycline, at $5.5 \mathrm{mg} \mathrm{kg}^{-1}$ [31]. However, the presence of oxytetracycline may be surprising, because in Poland there are no approved medicated premixes with this antibiotic to manufacture medicated feed; thus, it may suggest the illegal use of oxytetracycline on farms. This could be confirmed by quantified relatively high concentrations ranging from 0.9 to $49 \mathrm{mg} \mathrm{kg}^{-1}$. Moreover, two feed samples contained doxycycline together with tylosin at concentrations of 7.9 and $10.9 \mathrm{mg} \mathrm{kg}^{-1}$ and 3.7 and $0.4 \mathrm{mg} \mathrm{kg}^{-1}$, respectively, indicating either the illegal use of the antibiotics or cross-contamination. Cross-contamination during the production process in feed mills 
can be an important reason for the contamination of feed with undeclared drugs [27,30]. In the survey described by Lynas et al., the most frequently detected contaminant was chlortetracycline which was found in $15.2 \%$ of all analysed feedingstuffs. Furthermore, a study conducted in the Netherlands confirmed that nonmedicated feed batches were contaminated with antibiotic residues such as tetracyclines, penicillins and sulfonamides [20]. Out of 140 analysed samples, 87\% of the samples contained detectable amounts of antibiotics, with the concentrations ranging from 0.1 to $154 \mathrm{mg} \mathrm{kg}^{-1}$. However, our own research revealed the unconscious use of chlortetracycline-contaminated feed on few pig farms. The feed was manufactured by a medicated-feed-producing mill. The concentrations of contaminating chlortetracycline were between $<0.3$ and $2.7 \mathrm{mg} \mathrm{kg}^{-1}$.

Usually, cross-contamination results in subtherapeutic concentrations in feeds which are unlikely to equal those prescribed for medication. In spite of this, they can sometimes be sufficient to cause violative residues in meat or meat products. Thus, the antibacterial substances that enter the feed via different paths can pass through the food chain to the consumers, causing possible allergic reactions, toxic effects and bacterial resistance problems. Feed contaminated with pharmacologically active substances can lead to the sale of food of animal origin containing drug residues, for which the zero level applies, or at concentrations greater than the authorized maximum residue limits MRLs. For example, Segato et al. [32] conducted studies in order to obtain information on the transfer of doxycycline to chicken tissues when feed contaminated by this antibiotic at the level of $4 \mathrm{mg} \mathrm{kg}^{-1}$ was administered to poultry. Under the adopted experimental conditions, the doxycycline concentrations in each tissue (muscle, liver, kidney) reached average levels lower than the corresponding MRL, but the analyte was present. This study showed the role played by feed; in the absence of the withdrawal period, contaminating drugs can pose a risk to the consumers due to the occurrence of residues.

Animal feeds must have the required quality, especially in the context of food chain safety. This is very significant in the event that antimicrobials might provoke allergies and contribute to the development of resistant bacterial strains if they reach the food chain. An exposure to low concentrations of antimicrobials may induce resistance in the normal gut bacteria of food animals, which could then be transferred to pathogenic organisms. Tetracyclines are one of the most commonly used groups of antibiotics in animal production. At the same time, they are categorized as highly important antimicrobials in human medicine [33]. The evidence for a link between non-human sources (animals, food, or the environment) and the potential to cause human disease is greatest for certain bacteria (e.g., non-typhoidal Salmonella, Campylobacter spp., Escherichia coli). Monitoring of antimicrobial resistance in commensal Escherichia coli isolated from slaughtered broilers, laying hens, turkeys, swine and cattle carried out in Poland between 2009-2012 revealed that antimicrobial resistance reached the highest values for tetracycline $(43.3 \%)$, followed by ampicillin $(42.3 \%)$ and ciprofloxacin $(39.0 \%)$ [34]. Researchers consider that antibiotic use in the life cycle of food animals makes it more likely that zoonotic foodborne bacteria such as Salmonella and Campylobacter harboured by the animals will be resistant to common antibiotics-especially if they are used at subtherapeutic concentrations. An increase in the prevalence of tetracycline-resistant Salmonella or Campylobacter strains may have implications for the antibiotic treatment of salmonellosis or campylobacteriosis cases in humans. However, studies carried out by Holman [31] indicated that chlortetracycline appears to have no effect on the measurable chlortetracycline resistance when given at a concentration of $5.5 \mathrm{mg} \mathrm{kg}^{-1} \mathrm{feed}_{\text {. }}$

\section{Materials and Methods}

\subsection{Sample Collection}

Feed samples were provided to the laboratory by inspectors, feed producers and animal holders and were collected from all over Poland. The samples were taken as a part of the national feed monitoring programme and commercial research. During 2013-2018, a total of 353 samples of feedingstuffs were analysed. This number was comprised of 52 samples of cattle feed, 138 samples of 
pig feed, 114 samples of poultry feed, 21 samples of concentrates/premixes and 28 samples of feed materials. The types of analysed samples are present in Table 1.

\subsection{Microbiological Plate Test}

In the first stage, the tetracycline antibiotics were detected by a microbiological 8-plate screening method for detection of antibacterial substances in animal feedingstuffs, which was developed and validated in our laboratory [16,35]. Combination of agar medium, $\mathrm{pH}$, and test microorganisms was optimised to yield a suitable sensitivity and optimal conditions for the detection of a single group of antibiotics. For tetracycline antibiotics, agar medium pH 6.0 and test microorganism Bacillus cereus ATCC 11778 were used. The limit of detection of this method for tetracyclines was $0.3 \mathrm{mg} \mathrm{kg}^{-1}$. To perform a sample assay, sterile petri dishes (diameter, $120 \mathrm{~mm}$ ) were filled with $20 \mathrm{~mL}$ of inoculated medium and left to harden at room temperature on a horizontal surface. When the agar was solidified, two wells were punched with a cork borer of $11 \mathrm{~mm}$ diameter on the plate. The plates were subjected to a quality control when unknown samples were analysed. Two antimicrobial disks (tetracycline $30 \mu \mathrm{g}$, Oxoid) were placed on the control petri dish to confirm standardization.

A ten-gram portion of the sample was then weighed into $200 \mathrm{~mL}$ Erlenmeyer flask. The samples were extracted with $50 \mathrm{~mL}$ of methanol/phosphate buffer $(\mathrm{pH} 8.0)$ mixture $(1: 1, v / v)$. The extraction time was $30 \mathrm{~min}$. After the extraction, the samples were centrifuged for $10 \mathrm{~min}$ at $3000 \times \mathrm{g}$ and $100 \mu \mathrm{L}$ of the supernatants was pipetted into wells on the agar surface on the plates. Test plates were incubated overnight at $30^{\circ} \mathrm{C}$, and then inspected for inhibition zones around the wells. Results of the microbiological assay were obtained by analysing the effect of diffusion on the agar medium inoculated with bacterial strain Bacillus cereus ATCC 11778. The presence of antibacterial substances was shown by the formation of growth inhibition zones around the punch hole after overnight incubation, as shown on Figure 6. The diameter of the zones was measured and a positive result was defined by an inhibition zone greater than $14 \mathrm{~mm}$. The samples showing growth inhibition zones on the test plate designed for TCs were suspicious of TCs and analysed and confirmed by liquid chromatography mass spectrometry.

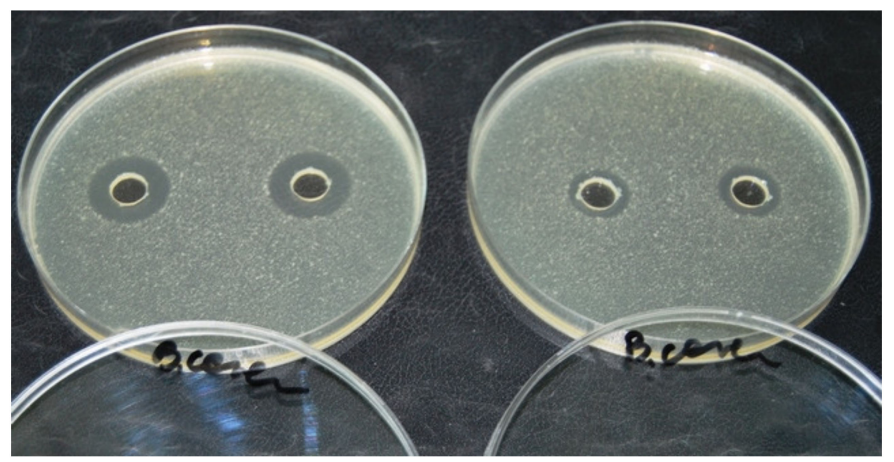

Figure 6. The presence of growth inhibition zones on B. cereus ATCC 11778 plates.

\subsection{Liquid Chromatography-Mass Spectrometry Analysis}

An analytical method for simultaneous determination of oxytetracycline, tetracycline, chlortetracycline and doxycycline using liquid chromatography-mass spectrometry was developed and validated as described by Patyra and Kwiatek [36].

The HPLC-MS consisted of HPLC Agilent 1200 and MS Agilent 6140 (Agilent Technologies, Santa Clara, CA, USA) controlled by the software ChemStation (Agilent Technologies, Santa Clara, CA, USA). The chromatographic analyses were performer by injecting $15 \mu \mathrm{L}$ of extract into a Kinetex C18 column $(100 \times 4.6$ mm i.d., $2.6 \mu \mathrm{m})$ (Phenomenex, Torrance, CA, USA). Mobile phases $\mathrm{A}$ and $\mathrm{B}$ were mixed on a gradient mode with a flow rate of $0.5 \mathrm{ml} \mathrm{min}{ }^{-1}$. The column temperature was 
set at $20^{\circ} \mathrm{C}$. Analytes were detected in positive electrospray mode (ESI+). The monitored precursor ions for OTC, TC, CTC and DC were 461, 445, 479 and $445 \mathrm{~m} / \mathrm{z}$, respectively.

\subsubsection{Chemicals, Reagents and Stock Solutions}

Oxytetracycline, tetracycline, chlortetracycline, doxycycline, formic acid and ethylenediaminetetraacetic acid disodium salt $\left(\mathrm{Na}_{2} \mathrm{EDTA}\right)$ were purchased from Sigma-Aldrich (St. Louis, MO, USA). Acetonitrile and methanol (HPLC grade) were purchased from J.T. Baker (Deventer, the Netherlands). Sodium hydroxide and sodium hydrogen phosphate were obtained from Avantor Performance Materials (Gliwice, Poland) and citric acid from Acros Organics (Geel, Belgium). All reagents used were of analytical grade and analytically pure. Water was deionised $\left(>18 \mathrm{M} \Omega \mathrm{cm}^{-1}\right)$ by the Milli-Q water purification system (Bedford, MA, USA).

The McIlvaine-Na ${ }_{2}$ EDTA buffer was prepared by dissolving $11.406 \mathrm{~g} \mathrm{Na}_{2}$ EDTA in $115.65 \mathrm{~mL}$ $0.2 \mathrm{M}$ phosphate buffer and $184.65 \mathrm{~mL} 0.1 \mathrm{M}$ citric acid. The $\mathrm{pH}$ was adjusted to 4.0 by adding $0.1 \mathrm{M}$ citric acid or $0.2 \mathrm{M}$ phosphate buffer. Mobile phase A consisted of Milli-Q water acidified to $0.1 \%$ with formic acid, and mobile phase B consisted of acetonitrile acidified to $0.1 \%$ with formic acid.

To prepare the individual stock solutions of tetracyclines, $10 \mathrm{mg}$ of tetracycline was dissolved in $10 \mathrm{~mL}$ of methanol and stored at $-20{ }^{\circ} \mathrm{C}$ for up to six months. A working standard solution of tetracyclines was prepared by diluting the stock solution of each tetracycline to yield a final concentration of $100 \mu \mathrm{g} \mathrm{mL}^{-1}$ (the purity was consider when calculating appropriate concentrations) and stored at $-20^{\circ} \mathrm{C}$ for up to six months.

\subsubsection{Sample Preparation and Clean-Up}

Firstly, matrix-matched calibration curves were prepared. Different volumes of the tetracyclines working solutions were added to $5 \mathrm{~g}$ blank feed samples. Concentrations of tetracyclines in the matrix-matched feed samples were $0,0.3,0.5,1.0,2.5$ and $5.0 \mathrm{mg} \mathrm{kg}^{-1}$.

To extract the tetracyclines from the feed samples, $5 \mathrm{~g}$ of grounded feed and $25 \mathrm{~mL}$ of McIlvaine- $\mathrm{Na}_{2}$ EDTA buffer were added to a $50 \mathrm{ml}$ polypropylene tube. After shaking for $45 \mathrm{~min}$ on a horizontal shaker, the sample was centrifuged at $4000 \times g$. Then, $5 \mathrm{~mL}$ of the supernatant was loaded onto a Strata-X-CW SPE cartridge ( $300 \mathrm{mg}, 3 \mathrm{~mL}$ ) that had been preconditioned with $3 \mathrm{~mL}$ of methanol and $3 \mathrm{~mL}$ of water. The cartridges were then rinsed with $6 \mathrm{~mL}$ of water, $6 \mathrm{~mL}$ of methanol and $3 \mathrm{~mL}$ of acetonitrile with $2 \%$ formic acid. The analytes were eluted with $3 \mathrm{~mL}$ of methanol with $2 \%$ formic acid. The eluate was evaporated to dryness under a nitrogen stream and the final residue was dissolved in $1 \mathrm{~mL}$ of $0.1 \%$ formic acid in water. Then, the extract was put into 2-mL autosampler vials and $15 \mu \mathrm{L}$ were injected into the HPLC-MS system.

\section{Conclusions}

In conclusion, animal feed can be screened for the presence of antibacterial substances, including tetracyclines with a microbiological inhibition test, using a solid medium at $\mathrm{pH} 6.0$ and B. cereus as a test organism. Confirmation with the HPLC technique is always necessary to gain information about the substance identification and quantification. Our study shows that tetracycline antibiotics may occur as contaminating agents in animal feed. A major implication of contamination of feed with undeclared antimicrobial agents is, firstly, the contribution to the development of bacteria resistant to drugs used to treat infections, and secondly, the risk concerning residues of antibiotics in edible tissues and products that can produce allergic or toxic reactions in consumers, particularly if it concerns antibiotics that are absorbed in the digestive tract $[37,38]$.

Author Contributions: Conceptualization, M.P.-S.; Methodology, M.P.-S. and E.P.; Investigation, E.P., A.G., M.C.-P. and B.K.; Writing Original Draft Preparation, M.P.-S.; Writing, Review and Editing, E.P. and K.K.; Supervision, K.K. All authors have read and agreed to the published version of the manuscript. 
Funding: The research was funded from the National Veterinary Research Institute's statutory sources.

Conflicts of Interest: The authors declare that there is no conflict of interest regarding the publication of this article.

\section{References}

1. Nielsen, P.; Gyrd-Hansen, P. Bioavailability of oxytetracycline, tetracycline and chlortetracycline after oral administration to fed and fasted pigs. J. Vet. Pharmacol. Ther. 1996, 19, 305-311. [CrossRef] [PubMed]

2. Williams, D.N. Tetracyclines. In Infectious diseases, 2nd ed.; Gorbach, S.L., Bartlett, J.G., Blacklow, N.R., Eds.; The W.B. Saunders Co.: Philadelphia, P, USA, 1998; pp. 227-231.

3. Chopra, I.; Roberts, M. Tetracyclines Antibiotics: Mode of Action, Applications, Molecular Biology, and Epidemiology of Bacterial Resistance. Microbiol. Mol. Biol. Rev. 2001, 65, 232-260. [CrossRef] [PubMed]

4. Samanidou, V.F.; Nikolaidou, K.I.; Papadoyannis, I.N. Development and validation of an HPLC confirmatory method for the determination of seven tetracycline antibiotics residues in milk according to the European Union Decision 2002/657/EC. J. Sep. Sci. 2007, 30, 2430-2439. [CrossRef] [PubMed]

5. Barton, M.D. Antibiotic use in animal feed and its impact on human health. Nutr. Res. Rev. 2000, 13, $279-299$. [CrossRef] [PubMed]

6. Wegener, H.C. Antibiotics in animal feed and their role in resistance development. Curr. Opin. Microbiol. 2003, 6, 439-445. [CrossRef] [PubMed]

7. Graham, J.P.; Boland, J.J.; Silbergeld, E. Growth Promoting Antibiotics in Food Animal Production: An Economic Analysis. Public Health Rep. 2007, 122, 79-87. [CrossRef] [PubMed]

8. Swann, M.M. Report of the Joint Committee on the Use of Antibiotics in Animal Husbandry and Veterinary Medicine; Her Majesty's Stationery Office: London, UK, 1969.

9. Witte, W. Medical Consequences of Antibiotics Use in Agriculture. Science 1998, 279, 996-997. [CrossRef]

10. Marschall, B.M.; Levy, S.B. Food Animals and Antimicrobials: Impacts on Human Health. Clin. Microbiol. Rev. 2011, 24, 718-733. [CrossRef]

11. Castanon, J.I.R. History of the use of antibiotic as growth promoters in european poultry feeds. Poultry Science 2007, 86, 2466-2471. [CrossRef]

12. Schnappinger, D.; Hillen, W. Tetracyclines: Antibiotic action, uptake, and resistance mechanisms. Arch. Microbiol. 1996, 165, 359-369. [CrossRef]

13. Grave, K.; Torren-Edo, J.; Muller, A.; Greko, C.; Moulin, G.; Mackay, D. Variations in the sales and sales patterns of veterinary antimicrobial agents in 25 European countries. J. Antimicrob. Chemother. 2014, 69, 2284-2291. [CrossRef] [PubMed]

14. European Medicines Agency. Sales of Veterinary Antimicrobial Agents in 31 European Countries in 2017; Trends from 2010 to 2017; Ninht ESVAC Report; European Medicines Agency: Amsterdam, The Netherlands, 2019.

15. Boscher, A.; Guignard, C.; Pellet, T.; Hoffmann, L.; Bohn, T. Development of a multi-class method for the quantification of veterinary drug residues in feedingstuffs by liquid chromatography-tandem mass spectrometry. J. Chromatogr. A 2010, 1217, 6394-6404. [CrossRef] [PubMed]

16. Przeniosło-Siwczyńska, M.; Patyra, E.; Chyłek-Purchała, M.; Kozak, B.; Kwiatek, K. Occurrence of tetracyclines in feedingstuffs-results of a two-year study within the official control of feed. Bull. Vet. Inst. Pulawy 2015, 59, 527-532. [CrossRef]

17. European Commission. Regulation (EC) No 1831/2003 of the European Parliament and of the Council of 22 September 2003 on Additives for Use in Animal Nutrition; OJ L268; European Commission: Brussels, Belgium, 2003; pp. 29-43.

18. European Commission. Regulation (EU) No 2019/4 of the European Parliament and of the Council of on the manufacture, placing on the market and use of medicated feed, amending Regulation (EC) No 183/2005 of the European Parliament and of the Council and repealing Council Directive 90/167/EEC; OJ L4; European Commission: Brussels, Belgium, 2019; pp. 1-23.

19. Kaklamanos, G.; Vincent, U.; von Holst, C. Analysis of antimicrobial agents in pig feed by liquid chromatography coupled to orbitrap mass spectrometry. J. Chromatogr. A 2013, 1293, 60-74. [CrossRef] [PubMed]

20. Stolker, A.A.M.; Manti, V.; Zuidema, T.; van Egmond, H.; Deckers, E.R.; Herbes, R.; Hooglugt, J.; Olde Heuvel, E.; de Jong, J. Carry-over of veterinary drugs from medicated to non-medicated feeds in commercial feed manufacturing plants. Food Addit. Contam. Part A 2013, 30, 1100-1107. [CrossRef] [PubMed] 
21. Mevius, D.J.; Sprenger, M.J.W.; Wegener, H.C. EU conference 'The Microbial Threat". Int. J. Antimicrob. Ag 1999, 11, 101-105. [CrossRef]

22. De Jong, J.; Tomassen, M.J.H.; van Egmond, H.J.; van Rhijn, J.A.; Zuidema, T.; Michard, J.; Genouel, C.; Brambilla, G.; Nunes da Costa, J.M.G.; Nordkvist, E.; et al. Towards a control strategy for banned antibiotics and growth promoters in feed: The SIMBAG-FEED project. In Antimicrobial Growth Promoters. Where do we go from here? 1st ed.; Barug, D., de Jong, J., Kies, A.K., Verstegen, M.W.A., Eds.; Wageningen Academic Publishers: Wageningen, The Netherlands, 2006; pp. 211-234.

23. De Wasch, K.; Okerman, L.; Croubels, S.; De Brabander, H.; Van Hoof, J.; De Backer, P. Detection of residues of tetracycline antibiotics in pork and chicken meat: Correlation between results of screening and confirmatory tests. Analyst 1998, 123, 2737-2741. [CrossRef]

24. Ghidini, S.; Zanardi, E.; Varisco, G.; Chizzolini, R. Residues of $\beta$-lactams antibiotics in bovine milk: Confirmatory analysis by liquid chromatography tandem mass spectrometry after microbial assay screening. Food Addit. Contam. 2003, 20, 528-534. [CrossRef]

25. Borras, S.; Companyo, R.; Granados, M.; Guiteras, J.; Perez-Vendrell, A.M.; Brufau, J.; Medina, M.; Bosch, J. Analysis of antimicrobial agents in animal feed. Trends Anal. Chem. 2011, 30, 1042-1064. [CrossRef]

26. Chico, J.; van Holthoon, F.; Zuidema, T. Ion Suppression Study for Tetracyclines in Feed. Chromatogr. Res. Int. 2012, 9. [CrossRef]

27. McEvoy, J.D.G. Contamination of animal feedingstuffs as a cause of residues in food: A review of regulatory aspects, incidence and control. Anal. Chim. Acta 2002, 473, 3-26. [CrossRef]

28. Kantiani, L.; Farre, M.; Grases i Freixiedas, J.M.; Barcelo, D. Determination of antibacterials in animal feed by pressurized liquid extraction followed by online purification and liquid chromatography-electrospray tandem mass spectrometry. Anal. Bioanal. Chem. 2010, 398, 1195-1205. [CrossRef] [PubMed]

29. Kirbiš, A. Microbiological screening method for detection of aminoglycosides, $\beta$-lactams, macrolides, tetracyclines and quinolones in meat samples. Slov. Vet. Res. 2007, 44, 11-18.

30. Lynas, L.; Currie, D.; McCaughey, W.J.; McEvoy, J.D.G.; Kennedy, D.G. Contamination of animal feedingstuffs with undeclared antimicrobial additives. Food Addit. Contamin. 1998, 15, 162-170. [CrossRef] [PubMed]

31. Holman, D.B.; Chenier, M.R. Impact of subtherapeutic administration of tylosin and chlortetracycline on antimicrobial resistance in farrow-to-finish swine. FEMS Microbiol. Ecol. 2013, 85, 1-13. [CrossRef] [PubMed]

32. Segato, G.; Benetti, C.; Angeletti, R.; Montesissa, C.; Biancotto, G. Doxycycline and sulfadimethoxine transfer from cross-contaminated feed to chicken tissues. Food Addit. Contamin. 2011, 28, 860-868. [CrossRef]

33. World Health Organization. Critically Important Antimicrobials for Human Medicine; 6th revision; World Health Organization: Geneva, Switzerland, 2019.

34. Wasyl, D.; Hoszowski, A.; Zając, M.; Szulowski, K. Antimicrobial resistance in commensal Escherichia coli isolated from animals at slaughter. Front. Microbiol. 2013, 4, 1-12. [CrossRef]

35. Przeniosło-Siwczyńska, M.; Kwiatek, K. Evaluation of multi-plate microbial assay for the screening of antibacterial substances in animal feedingstuffs. Bull. Vet. Inst. Pulawy 2007, 51, 599-602.

36. Patyra, E.; Kwiatek, K. Development and validation of multi-residue analysis of tetracycline antibiotics in feed by high performance liquid chromatography coupled with mass spectrometry. Food Addit. Contam. A 2017, 34, 1553-1561. [CrossRef]

37. Dewdney, J.M.; Maes, L.; Raynaud, J.P.; Blanc, F.; Scheid, J.P. Risk assessment of antibiotic residues of beta-lactams and macrolides in food products with regard to their immunoallergic potential. Food Chem. Toxicol. 1991, 29, 477-483. [CrossRef]

38. Berends, B.R.; van den Bogaard, A.E.; van Knapen, F.; Snijders, J.M. Human health hazards associated with the administration of antimicrobials to slaughter animals. Part I. An assessment of the risks of residues of tetracyclines in pork. Vet. Q. 2001, 23, 2-10. [CrossRef] [PubMed]

Sample Availability: Samples of the compounds are not available from the authors. 